\title{
Solvation enthalpy and the thermodynamics of hydration of trans-cyclohexyl-1,4-diamine and cis-cyclohexyl-1,2-diamine
}

\author{
Luciana I.N. Tomé ${ }^{a}$, A.J. Lopes Jesus ${ }^{\text {a }}$, R.A. Esteves de Castro ${ }^{b}$, M. Helena S.F. Teixeira ${ }^{a}$, \\ João Canotilho ${ }^{\text {b }}$, M. Ermelinda S. Eusébio ${ }^{\text {a,* }}$ \\ a Department of Chemistry, Rua Larga 3004-535, University of Coimbra, Portugal \\ ${ }^{\mathrm{b}}$ Faculty of Pharmacy, Rua do Norte 3000-295, University of Coimbra, Portugal
}

Received 7 May 2007; received in revised form 21 June 2007; accepted 10 July 2007

Available online 19 July 2007

Dedicated to Professor J. Simões Redinha on the occasion of his 80th birthday

\begin{abstract}
The enthalpy of solution of trans-cyclohexyl-1,4-diamine and cis-cyclohexyl-1,2-diamine in water was determined by calorimetry. The enthalpy of hydration was determined from this quantity and from the enthalpy of sublimation/vaporization presented in another paper by the authors. Considering the solvation process resulting from cavity creation in the solvent and variation of solute conformation transfer steps, the enthalpy corresponding to solute-solvent interaction was estimated. The entropies of solvation and interaction were calculated from the values given for the enthalpies in the present paper and those available for the Gibbs free energies.
\end{abstract}

(c) 2007 Elsevier Ltd. All rights reserved.

Keywords: trans-Cyclohexyl-1,4-diamine; cis-Cyclohexyl-1,2-diamine; Solution enthalpy; Solute-solvent interactions; Hydration thermodynamics

\section{Introduction}

Most chemical reactions with amines occur in solution, particularly in aqueous solutions. This means that chemists and biochemists often have to look straight at important (amine + water) systems. The key to interpreting these systems is the understanding of the interaction between the amine group and water.

This paper deals with the study of trans-cyclohexyl-1,4diamine and cis-cyclohexyl-1,2-diamine by calorimetric determination of the solution enthalpy. This work on cyclohexylamines is justified, in fact, because of their applications in laboratory and industrial synthesis, but the main aim of the paper is to learn about the influence of particular molecular features of amines on hydration. The two diamines under consideration provide information about the contributions of the polar and non-polar groups to

\footnotetext{
${ }^{*}$ Corresponding author. Tel.: +351 239854450; fax: +351 239827703.

E-mail address: quierme@ci.uc.pt (M.E.S. Eusébio).
}

the enthalpy of hydration, and about the effects of the orientation of $\mathrm{NH}_{2}$ relative to the cyclohexane ring and the proximity of the two polar groups on interaction with water.

The values of the enthalpy of solution and those determined for the enthalpy of sublimation/vaporization [1] allow the determination of the enthalpy corresponding to the transfer of the solute molecules from the gas state to solution (solvation enthalpy). The solvation enthalpy is then decomposed into three terms: (1) creation of the cavity in the solvent to accept the solute molecule, (2) variation of the solute's molecular conformation from the gas phase to the solution phase, (3) solute-solvent interaction. Since the enthalpies corresponding to steps (1) and (2) can be calculated, the solute-solvent interaction enthalpy is estimated from the solvation enthalpy.

Combining the enthalpic data with those available for the Gibbs free energy of hydration [2] the entropy is determined and a more complete thermodynamic discussion of the systems under consideration is undertaken. 


\section{Experimental and results}

The cyclohexyldiamines studied in this work were purchased from Fluka, and the specified purity corresponding to a mass fraction was $x \geqslant 0.99$ for trans-cyclohexyl-1,4-diamine and $x \geqslant 0.98$ for the $c i s-1,2$-isomer. Purity was checked by gas chromatography-mass spectrometry, using an HP Agilent 6890 chromatograph with an SGE HP-5MS column, and an HP 5973 MSD mass spectrometer, with an electron impact source. No impurities were detected in the trans-isomer, while $x=0.99$ was found for purity for cis-cyclohexyl1,2-diamine. The absence of water was checked by infrared spectroscopy using a Mattson infrared spectrometer and by differential scanning calorimetry using a Perkin Elmer Pyris 1 calorimeter. The substances studied were used without any further purification, kept in a dry atmosphere and handled in a glove box filled with dry nitrogen.

In order to suppress protonation reactions, $0.01 \mathrm{~mol} \cdot \mathrm{dm}^{-3}$ aqueous $\mathrm{NaOH}$ solution was used in the solution experiments. High purity water from a Millipore water purifier and $\mathrm{NaOH}(x \geqslant 0.99)$ from Fluka were used. Care was taken to avoid contamination by atmospheric carbon dioxide. All calorimetric experiments were performed at $T=298.15 \mathrm{~K}$.

Enthalpies of solution were determined using a Setaram C80 heat flux calorimeter. The concentration of the solutions ranged from $(m=0.06$ to 0.35$) \mathrm{mol} \cdot \mathrm{kg}^{-1}$. As amines react with the mercury used for sealing the standard reversal mixing cells, a special cell was constructed (figure 1). The following procedure was used in the cell assembly. A known amount of water is placed inside the $3 \mathrm{~cm}^{3}$ stainless steel compartment $\mathrm{A}$. The O-ring $\mathrm{a}^{\prime}$ is applied and the solute compartment $\mathrm{B}$ and $\mathrm{A}$ are screwed together. The sealing rod, C, is then applied (solvent compartment is then closed by stopper a). A known amount of the compound under study is inserted inside B. The sections D, E and B are afterwards connected together (solute compartment is now closed by stopper b). Finally, the cell is completely assembled by screwing in the handling rod F. The components are mixed by pulling rod $\mathrm{F}$ up. The amounts of solute and solvent were determined by weight.

The calorimetric system was calibrated using the enthalpy of solution in water of $\mathrm{KCl}[3,4]$ (Panreac, $x>0.995$ ), treated according to the recommendation for this standard [5]. The calorimetric precision was checked by measuring the heat evolved in the dissolution of tris(hydroxylmethyl)aminomethane (Tris) in $0.1 \mathrm{M} \mathrm{HCl}$ Tris $(x>0.999)$ purchased from Aldrich was kept in a desiccator over an aqueous saturated magnesium nitrate solution [6,7]. The value found for the dissolution of Tris in $0.1 \mathrm{M} \mathrm{HCl}$, solution concentration about $5 \mathrm{~kg} \cdot \mathrm{m}^{-3}$, was $\Delta_{\mathrm{sol}} H_{\mathrm{m}}=(-29.7 \pm 0.2) \mathrm{kJ} \cdot \mathrm{mol}^{-1}$ $(n=9)$. The literature value is $\Delta_{\text {sol }} H_{\mathrm{m}}=(-29.770 \pm$ $0.03) \mathrm{kJ} \cdot \mathrm{mol}^{-1}[3,6]$. Uncertainties in this work are expressed as one standard deviation unit.

The solution enthalpies of trans-cyclohexyl-1,4-diamine and cis-cyclohexyl-1,2-diamine in aqueous $0.01 \mathrm{M} \mathrm{NaOH}$ are presented in tables 1 and 2, respectively. No variation

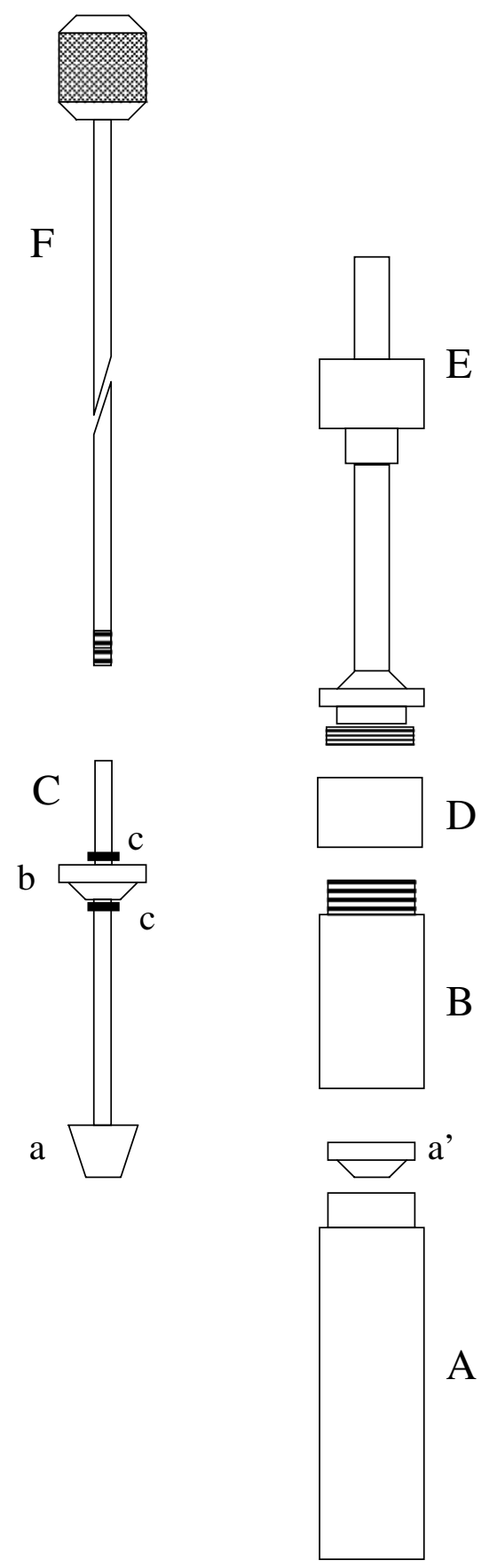

FIGURE 1. Solution calorimetry cell. A, solvent compartment; B, solute compartment; C, sealing rod; D and E, auxiliary joint; F, handling rod. a and b, Teflon stoppers; c, Viton O-ring; $\mathrm{a}^{\prime}$, Teflon O-ring.

of $\Delta_{\mathrm{sol}} H_{\mathrm{m}}$ with concentration was observed over the concentration ranges studied. The values of the standard enthalpies of solution, $\Delta_{\mathrm{sol}} H_{\mathrm{m}}^{\circ}$, are thus the mean of the values found experimentally, given in tables 1 and 2. To see the influence of the ionic strength on $\Delta_{\mathrm{sol}} H_{\mathrm{m}}$, experiments were carried out for trans-cyclohexyl-1,4-diamine in water and no significant differences were observed between the values obtained in water and in $0.01 \mathrm{M}$ aqueous $\mathrm{NaOH}$. Thus, the results obtained for $\Delta_{\mathrm{sol}} H_{\mathrm{m}}$ can be considered as the standard enthalpy of solution, $\Delta_{\mathrm{sol}} H_{\mathrm{m}}^{\circ}$. Calorimetric 
TABLE 1

Enthalpy of solution, $\Delta_{\mathrm{sol}} H_{\mathrm{m}}$, of trans-cyclohexyl-1,4-diamine in $0.01 \mathrm{~mol} \cdot \mathrm{dm}^{-3} \mathrm{NaOH}$, at $T=298.15 \mathrm{~K}$

\begin{tabular}{ll}
\hline$m /\left(\mathrm{mol} \cdot \mathrm{kg}^{-1}\right)$ & $\Delta_{\mathrm{sol}} H_{\mathrm{m}} /\left(\mathrm{kJ} \cdot \mathrm{mol}^{-1}\right)$ \\
\hline 0.0639 & -11.5 \\
0.0681 & -11.4 \\
0.0696 & -11.2 \\
0.0713 & -11.4 \\
0.0761 & -11.4 \\
0.0773 & -11.6 \\
0.0787 & -11.4 \\
0.0913 & -11.0 \\
0.0923 & -11.1 \\
0.0972 & -11.1 \\
0.1104 & -11.1 \\
0.1114 & -11.3 \\
0.1161 & -10.9 \\
0.1211 & -11.3 \\
0.1242 & -11.9 \\
0.1253 & -10.7 \\
0.1264 & -11.3 \\
0.1476 & -11.9 \\
0.1497 & -11.2 \\
0.1790 & -11.9 \\
0.1893 & -10.8 \\
0.2126 & -11.8 \\
0.2243 & -11.5 \\
0.2655 & -10.9 \\
0.3437 & -11.0 \\
\hline
\end{tabular}

TABLE 2

Enthalpy of solution, $\Delta_{\mathrm{sol}} H_{\mathrm{m}}$, of cis-cyclohexyl-1,2-diamine in 0.01 $\mathrm{mol} \cdot \mathrm{dm}^{-3} \mathrm{NaOH}$, at $T=298.15 \mathrm{~K}$

\begin{tabular}{ll}
\hline$m /\left(\mathrm{mol} \cdot \mathrm{kg}^{-1}\right)$ & $\Delta_{\mathrm{sol}} H_{\mathrm{m}} /\left(\mathrm{kJ} \cdot \mathrm{mol}^{-1}\right)$ \\
\hline 0.0848 & -34.0 \\
0.0899 & -34.6 \\
0.0927 & -34.7 \\
0.0989 & -33.5 \\
0.1317 & -34.0 \\
0.1377 & -34.6 \\
0.1593 & -34.5 \\
0.1630 & -33.9 \\
0.2207 & -33.9 \\
0.2580 & -33.7 \\
0.3463 & -34.5 \\
0.3590 & -33.5 \\
0.3756 & -34.6 \\
\hline
\end{tabular}

measurements of cis-cyclohexyl-1,2-diamine cannot be carried out in water because this amine is a stronger base and the protonated fraction is considerable.

\section{Calculation of the thermodynamic functions corresponding to solute-solvent interactions}

The standard solvation enthalpy of solute $\mathrm{A}$ is expressed by [8]

A (ideal gas, $c=1 \mathrm{~mol} \cdot \mathrm{dm}^{-3}$ )

$\rightarrow$ A (ideal dilute solution, $c=1 \mathrm{~mol} \cdot \mathrm{dm}^{-3}$ ).
The experimental vaporization/sublimation standard enthalpy values, $\Delta_{\text {vap }} H^{\circ}$ or $\Delta_{\text {sub }} H^{\circ}$, presented in this paper pertain to the process

$$
\begin{aligned}
& \text { A (solid, liquid, } p=0.1 \mathrm{MPa}) \\
& \quad \rightarrow \mathrm{A} \text { (ideal gas, } p=0.1 \mathrm{MPa} \text { ). }
\end{aligned}
$$

On the other hand the standard solution enthalpy values refer to

A (solid, liquid, $p=0.1 \mathrm{MPa}$ )

$$
\rightarrow \mathrm{A} \text { (ideal dilute solution, } m=1 \mathrm{~mol} \cdot \mathrm{kg}^{-1} \text { ). }
$$

The expression relating the enthalpies involved in the processes (1)-(3) is

$\Delta_{\text {solv }} H_{\mathrm{m}}^{\circ}=\Delta_{\text {sol }} H_{\mathrm{m}}^{\circ}-\Delta_{\text {sub } / \mathrm{vap}} H_{\mathrm{m}}^{\circ}+\mathrm{R} T(1-\alpha T)$,

where $\alpha$ is the thermal expansion of the solvent ( $\alpha=0.257 \cdot 10^{-3} \mathrm{~K}^{-1}$ at $T=298.15 \mathrm{~K}$ [9]). The last term in equation (4) accounts for the correction of the experimental thermodynamic quantities to the standard states used in the solvation enthalpy definition.

The values obtained for the enthalpies specified in equation (4) for both diamines are presented in table 3.

The enthalpy due to solute-solvent interaction, $\Delta_{\mathrm{int}} H_{\mathrm{m}}$, can be calculated from $\Delta_{\text {solv }} H_{\mathrm{m}}^{\circ}$. In fact, the two quantities can be related by the following expression $[10,11]$

$$
\Delta_{\text {int }} H_{\mathrm{m}}=\Delta_{\text {solv }} H_{\mathrm{m}}^{\circ}-\Delta_{\text {cav }} H_{\mathrm{m}}-\Delta_{\text {conf }} H_{\mathrm{m}} \text {, }
$$

where $\Delta_{\mathrm{cav}} H_{\mathrm{m}}$ is the enthalpy required to open a cavity in the solvent to hold the solute molecule and $\Delta_{\text {conf }} H_{\mathrm{m}}$ is the enthalpy corresponding to variation of the conformation of the solute molecule when it is transferred from the gas to the solvent.

The calculation of $\Delta_{\text {cav }} H_{\mathrm{m}}$ was based on the Scaled Particle Theory [12-14] using the sphere by sphere expression and the radii described according to the united atom topological model (UAHF) [15].

The $\Delta_{\text {conf }} H_{\mathrm{m}}$ is the difference between the conformational enthalpy in solution, $H_{\text {sol }}$, and the conformational enthalpy in gas, $H_{\mathrm{g}}$ :

$\Delta_{\text {conf }} H_{\mathrm{m}}=H_{\text {sol }}-H_{\mathrm{g}}$.

The first term of the right-hand side of (6) was calculated by the conductor-like polarisable continuum model (CPCM) [16-19] and the second term is determined by

TABLE 3

Enthalpy of solution at infinite dilution in water, $\Delta_{\mathrm{sol}} H_{\mathrm{m}}^{\circ}$, enthalpy of sublimation or vaporization, $\Delta_{\text {sub }} H_{\mathrm{m}}^{\circ}$ or $\Delta_{\mathrm{vap}} H_{\mathrm{m}}^{\circ}$, and enthalpy of solvation, $\Delta_{\text {solv }} H_{\mathrm{m}}^{\circ}$, at $T=298.15 \mathrm{~K}$, for cyclohexyldiamines

\begin{tabular}{lllll}
\hline Substance & $\begin{array}{l}\Delta_{\text {sol }} H_{\mathrm{m}}^{\circ} / \\
\left.\mathrm{kJ} \cdot \mathrm{mol}^{-1}\right)\end{array}$ & $\begin{array}{l}\Delta_{\mathrm{sub}} H_{\mathrm{m}}^{\circ} / \\
\left(\mathrm{kJ} \cdot \mathrm{mol}^{-1}\right)\end{array}$ & $\begin{array}{l}\Delta_{\mathrm{vap}} H_{\mathrm{m}}^{\circ} / \\
\left(\mathrm{kJ} \cdot \mathrm{mol}^{1}\right)\end{array}$ & $\begin{array}{l}\Delta_{\text {solv }} H / \\
\left(\mathrm{kJ} \cdot \mathrm{mol}^{-1}\right)\end{array}$ \\
\hline $\begin{array}{c}\text { trans- } \\
\text { Cyclohexyl- }\end{array}$ & $-11.3 \pm 0.3$ & $105.0 \pm 0.9^{a}$ & & -114.0 \\
$\begin{array}{c}\text { 1,4-diamine } \\
\text { cis-Cyclohexyl- } \\
\text { 1,2-diamine }\end{array}$ & $-34.2 \pm 0.4$ & & $62.2 \pm 1.1^{a}$ & -94.1 \\
\hline
\end{tabular}

${ }^{a}$ Reference [1]. 
TABLE 4

Enthalpies of cyclohexyldiamines in the gas phase, $H_{\mathrm{g}}$, and in aqueous solution, $H_{\text {sol }}$, at $T=298.15 \mathrm{~K}$

\begin{tabular}{lll}
\hline Substance & $H_{\mathrm{g}} /\left(\mathrm{kJ} \cdot \mathrm{mol}^{-1}\right)$ & $H_{\mathrm{sol}} /\left(\mathrm{kJ} \cdot \mathrm{mol}^{-1}\right)$ \\
\hline trans-Cyclohexyl-1,4-diamine & -909503.8 & -909502.9 \\
cis-Cyclohexyl-1,2-diamine & -909498.1 & -909495.0 \\
\hline
\end{tabular}

TABLE 5

Enthalpy of cavity formation, $\Delta_{\text {cav }} H$, enthalpy of solute conformational change, $\Delta_{\text {conf }} H$, and interaction enthalpy, $\Delta_{\text {int }} H$ of cyclohexyldiamines in water at $T=298.15 \mathrm{~K}$

\begin{tabular}{llll}
\hline Substance & $\begin{array}{l}\Delta_{\mathrm{cav}} H / \\
\left(\mathrm{kJ} \cdot \mathrm{mol}^{-1}\right)\end{array}$ & $\begin{array}{l}\Delta_{\mathrm{conf}} \mathrm{H} / \\
\left(\mathrm{kJ} \cdot \mathrm{mol}^{-1}\right)\end{array}$ & $\begin{array}{l}\Delta_{\mathrm{int}} H / \\
\left(\mathrm{kJ} \cdot \mathrm{mol}^{-1}\right)\end{array}$ \\
\hline $\begin{array}{l}\text { trans-Cyclohexyl-1,4- } \\
\text { diamine }\end{array}$ & 11.0 & 0.9 & -125.9 \\
$\begin{array}{l}\text { cis-Cyclohexyl-1,2- } \\
\text { diamine }\end{array}$ & 10.8 & 3.1 & -108.0 \\
\hline
\end{tabular}

TABLE 6

Gibbs free energy and entropy terms of hydration and solute-solvent interaction of cyclohexyldiamines at $T=298.15 \mathrm{~K}$

\begin{tabular}{llllc}
\hline Substance & $\begin{array}{l}\Delta_{\text {solv }} G_{\mathrm{m}}^{\circ} / \\
\left(\mathrm{kJ} \cdot \mathrm{mol}^{-1}\right)\end{array}$ & $\begin{array}{l}\Delta_{\text {solv }} S_{\mathrm{m}}^{\circ} / \\
\left(\mathrm{kJ} \cdot \mathrm{mol}^{-1}\right)\end{array}$ & $\begin{array}{l}\Delta_{\text {int }} G_{\mathrm{m}}^{\circ} / \\
\left(\mathrm{kJ} \cdot \mathrm{mol}^{1}\right)\end{array}$ & $\begin{array}{c}T \Delta_{\text {int }} S_{\mathrm{m}}^{\circ} / \\
\left(\mathrm{kJ} \cdot \mathrm{mol}^{-1}\right)\end{array}$ \\
\hline $\begin{array}{c}\text { trans-Cyclohexyl- } \\
\text { 1,4-diamine }\end{array}$ & $-42.7^{a}$ & -71.3 & -112.1 & -13.8 \\
$\begin{array}{c}\text { cis-Cyclohexyl- } \\
\text { 1,2-diamine }\end{array}$ & $-34.9^{a}$ & -59.2 & -108.0 & 0 \\
\hline
\end{tabular}

${ }^{a}$ Reference [2].

DFT calculations using the B3LYP hybrid functional [2022] and Dunning's correlation consistent polarised valence double- $\zeta$ basis set (aug-cc-pVDZ) [23,24]. The results obtained for $H_{\text {sol }}$ and $H_{\mathrm{g}}$ are given in table 4. The values found for $\Delta_{\text {cav }} H_{\mathrm{m}}, \Delta_{\text {conf }} H_{\mathrm{m}}$ and $\Delta_{\mathrm{int}} H_{\mathrm{m}}$ are presented in table 5 .

Since data on the Gibbs free energy of hydration for the conformers of the amines we are dealing with are available [2], the Gibbs free energy of the solute-solvent interaction of the conformers is calculated following the same procedure as that described above for the enthalpy. The weighted means of the Gibbs free energy of the conformers were taken as the values of this function for the respective amine.

The entropy of hydration and solute-solvent interaction were estimated from the Gibbs free energy and the enthalpy. Table 6 gives the Gibbs free energy and entropy of solvation and interaction for both diamines.

\section{Discussion}

Let us start the discussion by first considering the result obtained for trans-cyclohexyl-1,4-diamine. In this compound, the amine groups are far enough apart for their hydration layers to be considered independent of one another. The information on the hydration of the amine group drawn from it can therefore be taken as characteristic of this group, free from interference by other polar groups. The subsequent comparison of data obtained for the two cyclohexyldiamines then reveals the effects of the solutes' molecular differences on the interaction with water.

The difference between the values for $\Delta_{\text {solv }} H_{\mathrm{m}}^{\circ}$ and $\Delta_{\text {int }} H_{\mathrm{m}}$ shows that the former thermodynamic quantity does not give direct information on the solute-solvent interaction. The enthalpy required to form the cavity in the solvent has a considerable influence on the solvation process. In the case of 1,4-isomer, the variation of the solute molecular conformation in the gas to solution transfer is only $0.9 \mathrm{~kJ} \cdot \mathrm{mol}^{-1}$. This shows that the molecular structure of the solute in the gas phase is also the most favourable for interaction with water.

The contribution of the $\mathrm{NH}_{2}$ groups to $\Delta_{\text {int }} H_{\mathrm{m}}$ can be estimated by comparing this property in trans-cyclohexyl1,4-diamine and cyclohexylamine. Making the assumption that in both structures the interaction of the non-polar moiety with water is the same, which is quite a reasonable assumption, the value corresponding to $\Delta_{\text {int }} H_{\mathrm{m}}$ of the $\mathrm{NH}_{2}$ group is simply the difference between the values found for the di- and monoamine. The value of $\Delta_{\text {int }} H_{\mathrm{m}}$ for cyclohexylamine is not known. It however could be calculated from the values given for $\Delta_{\mathrm{sol}} H_{\mathrm{m}}^{\circ}=-22.52 \mathrm{~kJ} \cdot \mathrm{mol}^{-1}$ [25] and $\Delta_{\text {vap }} H_{\mathrm{m}}^{\circ}=-42.8 \mathrm{~kJ} \cdot \mathrm{mol}^{-1}$ [25] and that calculated for $\Delta_{\text {cav }} H_{\mathrm{m}}=10.0 \mathrm{~kJ} \cdot \mathrm{mol}^{-1}$. The $\Delta_{\text {int }} H_{\mathrm{m}}=-73.1 \mathrm{~kJ} \cdot \mathrm{mol}^{-1}$ was determined for cyclohexylamine. The difference between $\Delta_{\mathrm{int}} H_{\mathrm{m}}$ of trans-cyclohexyl-1,4-diamine and cyclohexylamine gives $-52.8 \mathrm{~kJ} \cdot \mathrm{mol}^{-1}$, which is the value assigned for the enthalpy of interaction of the $\mathrm{NH}_{2}$ group with water.

From the value of $\Delta_{\mathrm{int}} H_{\mathrm{m}}$ of trans-cyclohexyl-1,4-diamine and that estimated for the amine group, a decrease of $20.3 \mathrm{~kJ} \cdot \mathrm{mol}^{-1}$ is found for the interaction of the nonpolar part of the diamine with water. This result is smaller than that estimated for cyclohexane from the experimentally determined enthalpy of solvation of this compound $\left(\Delta_{\text {solv }} H_{\mathrm{m}}^{\circ}=-33.2 \mathrm{~kJ} \cdot \mathrm{mol}^{-1}\right) \quad[26]$ or that calculated $\left(\Delta_{\text {solv }} H_{\mathrm{m}}^{\circ}=-27.9 \pm 1.2 \mathrm{~kJ} \cdot \mathrm{mol}^{-1}\right)$ [27] and from the cavity enthalpy $\left(\Delta_{\mathrm{cav}} H_{\mathrm{m}}=7.1 \mathrm{~kJ} \cdot \mathrm{mol}^{-1}\right)$. It is not surprising that the substitution of two hydrogens in cyclohexane by two amine groups leads to a decrease in the interaction of the non-polar part with water.

On the basis of the enthalpy, the interaction of transcyclohexyl-1,4-diamine arises fundamentally from the interaction of the polar groups with water. Both the amine group and the water molecule are able to participate in hydrogen bonding acting either as proton donor or acceptor.

Some authors have given evidence for the role of the hydrogen bonds in the interaction between the amine group and water. Using quantum chemical calculations, Marten et al. [28] have pointed out the stronger proton acceptor character of $\mathrm{NH}_{2}$ compared with that of water and the weaker proton donation of $\mathrm{N}-\mathrm{H}$ compared with $\mathrm{O}-\mathrm{H}$. Thus, the main interactions of $\mathrm{NH}_{2}$ with water are $\mathrm{H}_{2} \mathrm{O} \cdots \mathrm{NH}_{2}$ and $\mathrm{N}-\mathrm{H} \cdots \mathrm{OH}_{2}$ hydrogen bonds, being the first stronger than the second one. In a previous work carried out within this research centre, it has been shown that 
the stronger interaction of $\mathrm{NH}_{2}$ with water is that established between $\mathrm{O}-\mathrm{H}$ of the water and the non-bonded electron pair of the nitrogen [2].

The value of $\Delta_{\text {solv }} H_{\mathrm{m}}$ is much more negative than that of $\Delta_{\text {solv }} G_{\mathrm{m}}$ owing to unfavourable $\Delta_{\text {solv }} S_{\mathrm{m}}$, which makes the enthalpy the most sensitive property in the investigation of solute-solvent interaction.

Calculations of the solvation entropy of different solutions using various methods indicated that this thermodynamic property is due to the cavity formation [27,29-31]. In the system under discussion, the main contribution is, in fact, the cavity creation. However, the solute-solvent interactions also play a significant part. The water molecules in the hydration layer of the polar groups are less free than in pure water.

The cavitation enthalpy of cis-cyclohexyl-1,2-diamine is practically the same as that of the other isomer. Unlike the 1,4-isomer, the structure of the cis-cyclohexyl-1,2-diamine molecule in solution differs from that in the gas phase, as is shown by $\Delta_{\text {conf }} H_{\mathrm{m}}$. As the cyclohexane ring is an almost rigid structure, the structural difference occurs only in the $\mathrm{NH}_{2}$ orientation. The conformation in the gas state does not really favour hydrogen bonding with water.

The smaller distance between the polar groups and the axial orientation of the $\mathrm{NH}_{2}$ relative to the ring are the factors accounting for the less negative values of $\Delta_{\mathrm{int}} H_{\mathrm{m}}$ observed for cis-cyclohexyl-1,2-diamine. Both provide disadvantages in the interaction of this compound with water. When the $\mathrm{NH}_{2}$ groups are connected to neighbouring carbon atoms, mutual interactions occur between them in the gas state [32]. A stronger interaction between the hydrated groups is expected. Furthermore, the axial orientation places the amine group in a space crowded with the axial $\mathrm{CH}$ groups of the cyclohexyl ring. The hydration layer of the $\mathrm{NH}_{2}$ with this orientation becomes more difficult. The equatorial $\mathrm{NH}_{2}$ has a larger surface area exposed to water contact and therefore a higher hydration.

The values presented in table 6 indicate that in cis-cyclohexyl-1,2-diamine the solvation entropy is entirely due to the cavity formation process.

\section{Conclusions}

The stepwise decomposition of the enthalpy of solution into cavity function and variation of the solute molecular conformation allows the determination of enthalpy corresponding to solute-solvent interaction, a meaningful term in solvation study.

From the comparison of the enthalpies of interaction between trans-cyclohexyl-1,4-diamine and that calculated for cyclohexylamine from the data available in literature, the contribution of the amine and cyclohexyl groups are, respectively, $-53 \mathrm{~kJ} \cdot \mathrm{mol}^{-1}$ and $-20 \mathrm{~kJ} \cdot \mathrm{mol}^{-1}$.

The fall in the interaction enthalpy from trans-cyclohexyl-1,4-diamine to cis-1,2 isomer is $18 \mathrm{~kJ} \cdot \mathrm{mol}^{-1}$. This difference is ascribed to the interference between the hydra- tion layers and the less favourable orientation of the axial amine group.

The enthalpy data presented in this paper for the two diamine isomers are a valuable contribution towards understanding the aqueous solutions of these compounds. The values for the Gibbs free energy of the systems under study have already been published. From the values of these properties, the entropy is determined.

The hydration process is more enthalpic than entropic. In the 1,2-diamine, the entropy is entirely due to the cavity creation, whereas in the 1,4-isomer although most entropy comes from cavitation a significant fraction is related to the interaction.

The cavity creation and the solute conformation, besides being quantities needed to calculate the interaction terms, also give information on the hydration processes. The conformation enthalpy provides evidence for the variation of the solute's intrinsic structure when the solute is transferred from the gas phase to the water phase.

\section{Acknowledgements}

The authors are indebted to Professor J. Simões Redinha for very helpful discussions and for his great enthusiasm, encouragement and insight. Luciana I.N. Tomé acknowledges Fundação para a Ciência e a Tecnologia (FCT), Lisbon, for financial support, Grant SFRH/BD/ $12373 / 2003$.

\section{References}

[1] L.I.N. Tomé, M.T.S. Rosado, S.C.C. Nunes, T.M.R. Maria, J. Canotilho, M.E.S. Eusébio, J. Chem. Thermodyn. 39 (2007) 13541356.

[2] A.J.L. Jesus, L.I.N. Tomé, M.E.S. Eusébio, M.T.S. Rosado, J.S. Redinha, J. Phys. Chem. A 111 (2007) 3432-3437.

[3] R. Sabbah, X.W. An, J.S. Chickos, M.L.P. Leitão, M.V. Roux, L.A. Torres, Thermochim. Acta 331 (1999) 93-204.

[4] M.V. Kilday, J. Res. Natl. Bur. Stand. 85 (1980) 449-465.

[5] F. Goffredi, M. Goffredi, V.T. Liveri, J. Solution Chem. 24 (1995) 813-826.

[6] E.J. Prosen, M.V. Kilday, J. Res. Natl. Bur. Stand. 77A (1973) 581597.

[7] C.E. Vanderzee, D.H. Waugh, N.C. Haas, J. Chem. Thermodyn. 13 (1981) 1-12.

[8] A. Ben-Naim, Y. Marcus, J. Chem. Phys. 81 (1984) 20162027.

[9] Y. Marcus, Ion Solvation, John Wiley \& Sons, Chichester, 1985.

[10] F.S. Costa, M.E.S. Eusébio, J.S. Redinha, M.L.P. Leitão, J. Chem. Thermodyn. 32 (2000) 311-317.

[11] A.J.L. Jesus, L.I.N. Tomé, M.E.S. Eusébio, J.S. Redinha, J. Phys. Chem. B 110 (2006) 9280-9285.

[12] R.A. Pierotti, J. Phys. Chem. 67 (1963) 1840-1845.

[13] R.A. Pierotti, J. Phys. Chem. 69 (1965) 281-288.

[14] R.A. Pierotti, Chem. Rev. 76 (1976) 717-726.

[15] V. Barone, M. Cossi, J. Tomasi, J. Chem. Phys. 107 (1997) 32103221.

[16] M. Cossi, N. Rega, G. Scalmani, V. Barone, J. Comput. Chem. 24 (2003) 669-681.

[17] A. Klamt, G. Schuurmann, J. Chem. Soc. Perkin Trans. 2 (1993) 799 805.

[18] V. Barone, M. Cossi, J. Phys. Chem. A 102 (1998) 1995-2001. 
[19] M. Cossi, V. Barone, R. Cammi, J. Tomasi, Chem. Phys. Lett. 255 (1996) 327-335.

[20] A.D. Becke, Phys. Rev. A 38 (1988) 3098-3101.

[21] A.D. Becke, J. Chem. Phys. 98 (1993) 5648-5652.

[22] C.T. Lee, W.T. Yang, R.G. Parr, Phys. Rev. B 37 (1988) 785-789.

[23] D.E. Woon, T.H. Dunning Jr., Chem. Phys. 98 (1993) 1358-1371.

[24] T.H. Dunning Jr., J. Chem. Phys. 90 (1989) 1007-1023.

[25] S. Bergstrom, G. Olofsson, J. Solution Chem. 4 (1975) 535-555.

[26] S.J. Gill, F.N. Nichols, I. Wadso, J. Chem. Thermodyn. 8 (1976) 445-452.

[27] E. Gallichio, M.M. Kubo, R.M. Levy, J. Phys. Chem. B 104 (2000) $6271-6285$
[28] B. Marten, K. Kim, C. Cortis, R.A. Friesner, R.B. Murphy, M.N. Ringnalda, D. Sitkoff, B. Honig, J. Phys. Chem. 100 (1996) 1177511788.

[29] C. Amovilli, B. Mennucci, J. Phys. Chem. B 101 (1997) 1051-1057.

[30] I.T. Oliveira, S.J. Wodak, J. Chem. Phys. 111 (1999) 8576-8587.

[31] A.A.C.C. Pais, A. Sousa, M.E.S. Eusébio, J.S. Redinha, Phys. Chem. Chem. Phys. 3 (2001) 4001-4009.

[32] L.I.N. Tomé, M.T.S. Rosado, M.E.S. Eusébio, J.S. Redinha, J. Molec. Struct. THEOCHEM. 804 (2007) 65-74.

JCT $07-155$ 